ISSN 2236-0859

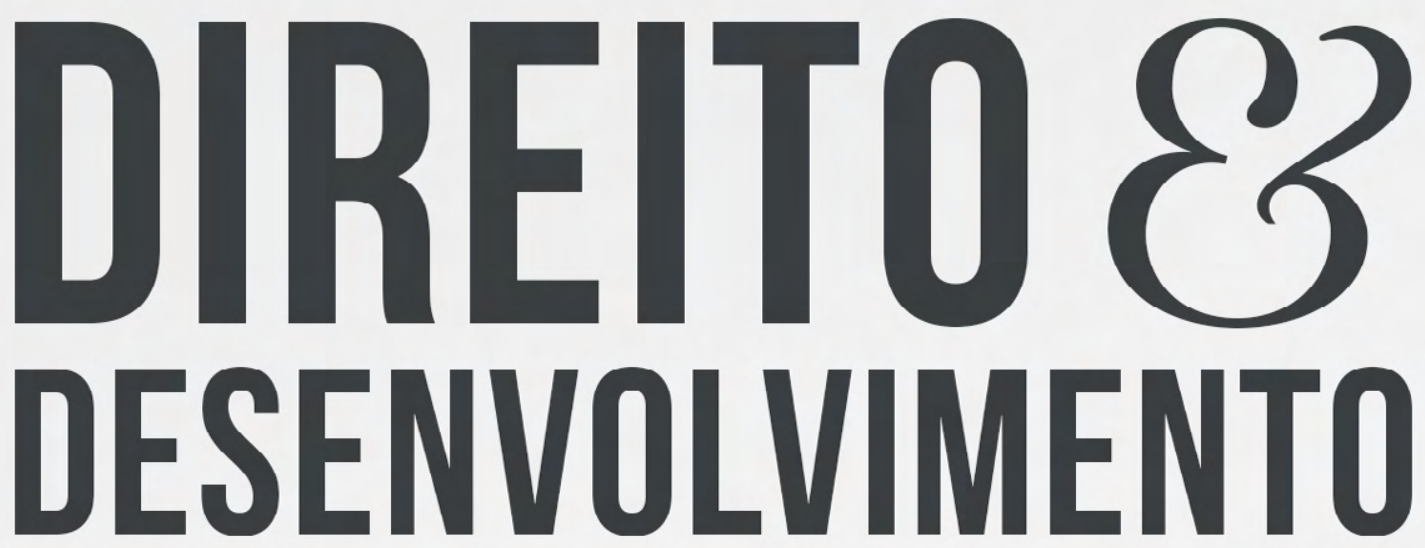

REVISTA DO PROGRAMA DE PÓS-GRADUAÇÃO EM DIREITO MESTRADO EM DIREITO E DESENVOLVIMENTO SUSTENTÁVEL

A ERA DAS NANOTECNOLOGIAS NOMERCADO CONSUMIDOR: A INSERCÇODOSO "NANOPRODUTOS" AO COTIDIANO EO DIREITO À INFORMAÇÃO

DANELE WEBER DA SILVA LEAL

RAQUEL VONHOHENDORFF 


\title{
A ERA DAS NANOTECNOLOGIAS NO MERCADO CONSUMIDOR: A INSERÇÃO DOS “NANOPRODUTOS” AO COTIDIANO E O DIREITO À INFORMAÇÃO
}

\author{
THE NANOTECHNOLOGIES ERA IN THE CONSUMER \\ MARKET: THE INSERTION OF “NANOPRODUCTS” TO THE \\ DAILY AND THE RIGHT TO INFORMATION
}

Recebido: 29/07/2018

Aprovado: $11 / 10 / 2018$

Daniele Weber da Silva Leal* Raquel Von Hohendorff**

RESUMO: As nanotecnologias são um novo e revolucionário conjunto de tecnologias, que trabalham na bilionésima parte do metro, elaborando produtos novos, com características físico-químicas desconhecidas, submetendo o consumidor a riscos incalculáveis. Estes produtos são lançados no mercado todos os dias e apenas uma pequena parcela dos consumidores possui algum tipo de informação. A sociedade tem o direito fundamental de saber a composição dos produtos do mercado, e este é um pré-requisito para o exercício do direito de escolher o que consumir. Portanto, a informação sobre o risco nanotecnológico chega ao consumidor? O Direito à informação está sendo respeitado neste contexto das nanotecnologias? Existe na legislação brasileira algum instrumento que fomente a proteção do consumidor face este direito? Será utilizado o método de abordagem fenomenológico-hermenêutico e como métodos de procedimento o histórico e o comparativo, além da pesquisa bibliográfica e legislativa e textos normativos de diversos organismos internacionais. Como hipótese provisória, observa-se no cenário brasileiro dispositivos legais e constitucionais que fomentam o Direito à Informação ao nanoconsumidor, fazendo jus ainda à precaução exigida nesta complexidade, preconizando também a gestão do risco.

Palavras-chave: Direito à informação. Nanotecnologias. Mercado consumidor. Código de defesa do consumidor.

\begin{abstract}
Nanotechnologies are a new and revolutionary set of technologies that work on the billionth of the meter, developing new products with unknown physicochemical characteristics, subjecting the consumer to incalculable risks. These products are launched on the market every day and only a small portion of consumers have some kind of information. Society has the fundamental right to know the composition of products on the market, and this is a prerequisite for exercising the right to choose what to consume. So the information on nanotechnology risk reaches the consumer? Is the right to information being respected in this context of nanotechnologies? Is there in Brazilian law any instrument that promotes consumer protection against this right? The method of phenomenological-hermeneutic approach will be used as methods of historical and comparative procedures, as well as bibliographical and legislative

\footnotetext{
* Doutoranda e Mestra pelo Programa de Pós-Graduação em Direito - Mestrado e Doutorado - da UNISINOS, vinculada à Linha de Pesquisa "Sociedade, Novos Direitos e Transnacionalização"; Especialista em Direito Público pelo Instituto de Educação RS (LFG). Graduada pela Unisinos. Integrante do Grupo de Pesquisa JUSNANO(CNPq); Professora da FACCAT -Faculdades Integradas de Taquara-RS, nas disciplinas Metodologia Científica e do curso de Direito, Bioética e Biodireito e Ética Profissional; Advogada. E-mail: weber.daniele@yahoo.com.br

** Doutora e Mestra em Direito pelo Programa de Pós-Graduação em Direito - Mestrado e Doutorado - da Unisinos/RS. Especialista e na graduação-Unisinos. Advogada. E-mail: vetraq@gmail.com
} em Processo e Direito do Trabalho pela UNISINOS. Integrante do Grupo de Pesquisa JUSNANO(CNPq); Professora do mesmo PPG
\end{abstract}


research and normative texts of various international organizations. As a provisional hypothesis, it is observed in the Brazilian scenario legal and constitutional devices that promote the Right to Information to the nonstick consumer, while still being fair to the precaution required in this complexity, also recommending risk management.

Keywords: Information's right. Nanotechnologies. Consumer market. Consumer protection code.

\section{INTRODUÇÃO}

As nanotecnologias representam a utilização da escala nanométrica - que equivale à bilionésima parte do metro - em variados setores e segmentos da indústria, gerando produtos com características totalmente novas, se equiparadas àquelas que seus similares em escala macro apresentam.

Este texto pretende estudar os contornos do direito à informação - contemplado no art.31, do CDC e Constituição Federal de 1988 - frente ao ingresso crescente de produtos desenvolvido a partir das nanotecnologias no mercado consumidor.

As nanos são apresentadas como um novo e revolucionário conjunto de tecnologias, operando numa escala sempre existente na natureza, mas somente viabilizadas ao ser humano a partir do final do Século XX, dado o desenvolvimento de equipamentos em condições de vislumbrar na ordem de um bilionésimo do metro.

Nesta ordem de grandeza, as propriedades físico-químicas das coisas sofrem modificações consideráveis, como a maior condutividade elétrica, aumento da resistência dos materiais, quanto menor for a superfície maior é a concentração de átomos e moléculas na camada superficial, novos resultados na interação dos materiais com o meio ambiente e o ser humano, provocando efeitos tóxicos ainda pouco conhecidos, o material que na escala maior é estável, isolante e opaco, na escala nano poderá ser reativo, condutor e transparente.

Por outro lado, as possibilidades financeiras destas aplicações são quase infinitas, podendo proporcionar um desenvolvimento econômico sem precedentes na história da humanidade. Aí se tem o desenho do desafio que as nanotecnologias estão trazendo para a sociedade contemporânea: ganhos econômicos e possibilidade de atendimento às necessidades humanas mostram-se quase ilimitados, mas com a potencialização de riscos invisíveis e incalculáveis, que poderão destruir o Planeta Terra, inviabilizando a própria continuidade da vida.

Esta é a encruzilhada que se desenha para o Direito e as demais áreas do conhecimento envolvidas com a Revolução Nanotecnocientífica, ou seja, encontrar alternativas seguras e responsáveis para lidar com o presente-futuro da vida de todos os seres vivos sobre a face da Terra, permitindo o aproveitamento saudável das contribuições científicas produzidas pela inteligência humana.

O problema que se pretende enfrentar: sob quais condições o direito à informação que já integra a legislação consumerista brasileira poderá disciplinar a instalação segura no mercado consumidor? A hipótese de trabalho, a partir deste problema, é: levando-se em conta todos os elementos que compõem o direito à informação do consumidor inscritos no CDC e $\mathrm{CF} / 88$, se devidamente aplicados poderão assegurar um aceitável nível de segurança para o nanoconsumidor.

Dentre os objetivos deste trabalho se encontra a divulgação do potencial inovador das nanotecnologias; a pesquisa sobre produtos que já tragam no seu conteúdo e/ou no processo 
produtivo alguma nanopartícula; estudar os elementos componentes do direito à informação, especialmente a partir do art. 31, do CDC; discutir algumas pesquisas que apontam riscos no tocante às nanopartículas.

O trabalho será desenvolvido a partir do método de abordagem denominado método fenomenológico-hermenêutico; como métodos de procedimento se utilizarão: método histórico, comparativo e estudo de caso; as técnicas de pesquisa manejadas são: pesquisa bibliográfica, legislativa e jurisprudencial.

A hipótese provisória é a de que, caso o fabricante respeite todos os ingredientes que se encontram no artigo 31, do CDC, pode-se concluir que as nanotecnologias chegarão ao mercado consumidor, permitindo uma escolha adequada, dentro de um nível humana e ambientalmente tolerável, a partir de uma relação de responsabilidade prospectiva entre os pesquisadores, fabricantes e consumidores e uma adequada gestão dos riscos presentes e futuros.

Todos acabam sendo consumidores de "nano produtos". No entanto, uma pequena parcela destes "todos" sabe alguma coisa sobre as nanotecnologias. Portanto, aí se desenha um importante espaço para o alinhamento dos contornos do chamado "direito à informação".

\section{AS NOVIDADES DA ERA NANOTECNOLÓGICA: DOS BENEFÍCIOS À POTENCIALIDADE DOS RISCOS}

As nanotecnologias representam um conjunto de ações de pesquisa, desenvolvimento e inovação, obtidas graças ao desenvolvimento de equipamentos especiais ${ }^{2}$, que conseguem acessar as propriedades especiais da matéria organizada a partir de estruturas de dimensões nanométricas ${ }^{3}$, isto é, um nanômetro corresponde à bilionésima parte de um metro ou à notação científica de $10^{-9}$. A expressão nanotecnologia deriva do prefixo grego nános, que significa anão, techne que equivale a ofício, e logos que expressa conhecimento. Atualmente, as variadas tecnologias que viabilizam a operação em escala nano trazem consigo muitas incertezas, especialmente concernentes à possibilidade de riscos altamente nocivos à saúde e ao meio ambiente (DURÁN; MATTOSO; MORAIS, 2006). Observando-se as características da Quarta Revolução Industrial, percebe-se que seus impactos terão reflexos nas inter-relações entre o homem e a tecnologia (os impactos em relação ao indivíduo, ao poder, a política e a economia e os reflexos sobre a cultura, sociedade e o meio ambiente). (ENGELMANN, 2017, p.248).

Estas novas tecnologias estão em quase todos os setores produtivos, que se encontram disponíveis na atualidade. O que está contido nesta palavra? A manipulação e a produção na escala atômica, ou seja, na bilionésima parte do metro, que equivale à notação científica $10^{-9}$. De acordo com o Comitê Técnico 229 da ISO (International Organization for Standardization), a utilização da escala nanométrica pode ser encontrada nos seguintes setores, aqui exemplificativamente apresentados: têxteis, plásticos, embalagens para alimentos, agricultura (SUPAN, 2015) material de construção, medicamentos, diagnóstico de doença, protetores solares, medicamentos, equipamentos médicos (ABBONDANZA, 2015, p.6) e odontológicos,

\footnotetext{
2 Como microscópios de varredura eletrônica e outros "nanoscópios”, que tem condições de permitir que se visualize a escala nanométrica, que está na escala atômica.

3 "Los nanomateriales no son nuevos, y no todos son sintéticos: están presentes en la naturaleza y están en todas partes. Lo que sí resulta novedoso es nuestra capacidad para manipular esos materiales comunes con un objetivo funcional. En el mundo natural, los nanomateriales aparecen en el esqueleto del plancton marino y los corales; en el pico y las plumas de las aves; en el pelo y la matriz ósea de los animales, incluida la especie humana; en las telas de araña; en las escamas y las alas; e incluso en el papel, la seda y el algodón. También existen en la naturaleza nanomateriales inorgánicos como ciertas arcillas, las cenizas volcánicas, el hollín, el polvo interestelar y determinados minerales. Los nanomateriales naturales son fundamentalmente el resultado de una serie de procesos químicos, fotoquímicos, mecánicos, térmicos y biológicos." (PNUMA, 2017, p. 24).
} 
energia, equipamentos esportivos, equipamentos bélicos e equipamentos eletrônicos (ISO TC 229,2018).

A nanotecnologia exibe um alto grau de interdisciplinaridade. Biólogos, químicos, físicos, médicos e engenheiros contribuem com suas experiências e ideias para gerar aplicações e produtos inovadores para a sociedade. Isso requer uma colaboração intensiva baseada na divisão do trabalho e um alto nível de compreensão de outras disciplinas (GERMANY, 2016), onde se situa o Direito e outras Ciências Sociais Aplicadas e também as denominadas Ciências Humanas.

Podeainda ser definida como a ciência da manipulação de matéria na escala nanométrica, a fim de descobrir novas propriedades e assim produzir novos produtos. Nos últimos 30 anos, uma quantidade considerável de interesse científico e financiamento de pesquisa e desenvolvimento dedicado à nanotecnologia levou a desenvolvimentos rápidos em todas as áreas de ciência e engenharia, incluindo química, materiais, energia, medicina, biotecnologia, agricultura, alimentos, dispositivos eletrônicos e produtos de consumo. Somente nos EUA, o governo federal gastou mais de US \$ 22 bilhões em pesquisa em nanotecnologia desde 2001 (CHENG et al, 2016).

Os avanços nas áreas de nanociência e nanotecnologia resultaram em inúmeras possibilidades para aplicações de produtos de consumo, muitas dos quais já migraram de bancos de laboratório para prateleiras de lojas e sites de comércio eletrônico. Os nanomateriais foram cada vez mais incorporados aos produtos de consumo, embora a pesquisa ainda esteja em andamento sobre seus potenciais efeitos no meio ambiente e na saúde humana (VANCE et al, 2015).

O tema das nanotecnologias integra a Estratégia do Programa Quadro Horizonte 2020 da União Europeia (UNIÃO EUROPEIA, 2014, p.o9-10), estabelecendo expressamente:

As tecnologias facilitadoras essenciais, como, por exemplo, a indústria de ponta e de materiais avançados, a biotecnologia e as nanotecnologias, estão no cerne dos produtos inovadores: telefones inteligentes, baterias de alto rendimento, veículos ligeiros, nanomedicamentos, tecidos inteligentes e muito mais. A indústria transformadora europeia é o maior empregador, com 31 milhões de trabalhadores em toda a Europa.-

Para demonstrar a gama de produtos existentes em nível global, é possível apresentar os números gerais registrados pela Nanotechnology Products Database (NPD) - Base de Dados de Produtos de Nanotecnologia (tradução nossa) -, criada em janeiro de 2016. Com a finalidade de se tornar uma fonte de informação confiável, acreditada e atualizada para a análise e caracterização de produtos nanotecnológicos (ou seja, nanoprodutos) introduzidos nos mercados globais, cataloga-se e registra-se toda capacidade de produção de nanotecnologia desenvolvida no mundo. Com base então na NPD, pode-se afirmar que atualmente existem 8219 produtos com nanotecnologias, produzidos por 1941 companhias, oriundos de 56 países. Desta forma, a nanotecnologia aparece diariamente na vida em sociedade, desde produtos cosméticos (protetor solar, creme antirrugas), shampoos, até mesmo produtos domésticos (bebedouro d'água) e medicamentos, indústria bélica, dentre outras várias áreas (INTRODUCTION, 2018).

A apresentação de novidades trazidas pela pesquisa ou desenvolvimento de novos produtos sempre acarreta um certo nível de risco (BARBAT, 2016, p.213). Para o Sistema do Direito, gera a necessidade de normatizar os riscos e os danos futuros com criatividade e modelos flexíveis, que possam ser facilmente modificados e atualizados em atendimento ao mesmo movimento das atualidades nanotecnológicas.

O que é um grande desafio, pois o Direito sempre avaliou os fatos do passado, atribuindo-lhes efeitos jurídicos no presente, determinando como deveria ser o comportamento 
no futuro. No caso das nanotecnologias, os efeitos que poderão surgir - riscos e danos - no futuro e no presente, ainda são pouco conhecidos ${ }^{4}$. E esse também é o problema da regulação legislativa estatal sobre a matéria: ainda não se tem informações científicas suficientes para uma regulação formal. Busca-se sinalizar quais seriam as possibilidades de (auto)regulação para esse cenário de riscos, muitos dos quais ainda desconhecidos, que projetam para o futuro uma eventualidade de ocorrência de danos.

O tamanho pequeno dos nanomateriais leva à preocupação sobre se eles podem atravessar membranas biológicas e, assim, ser tomadas por células e órgãos. Além disso, partículas pequenas podem se acumular profundamente nos pulmões se inaladas e permanecer lá por um longo período, porque eles são limpos lentamente a partir desta parte do pulmão. Existe também a preocupação de que o aumento da reatividade de materiais conhecidos na nanoforma pode levar a efeitos aumentados ou indesejados nos seres humanos e no ambiente (CHRISTENSEN, 2015).

Em razão do tamanho os materiais passam a ser regidos por leis físicas muito diferentes daquelas com as quais a ciência está habituada, abrindo possibilidades de que as nanopartículas apresentem maior grau de toxicidade do que em tamanhos maiores, esta é a razão pela qual existe a necessidade de se avaliar os riscos que existem decorrentes da manipulação, desenvolvimento e aplicação destas novas tecnologias, observando a toxicidade, os métodos apropriados para testes em toxicidade, bem como os impactos na saúde humana e ambiental (HOHENDORFF, ENGELMANN, 2014. p. 26-27.)

A entrada da nanotecnologia na fabricação de objetos tem sido comparada com o advento das tecnologias anteriores que têm afetado profundamente as sociedades modernas, tais como plásticos, semicondutores e até mesmo a eletricidade. Aplicações da nanotecnologia prometem melhorias transformadoras em desempenho materiais e longevidade para a eletrônica, medicina, energia, construção, máquinas-ferramentas, agricultura, transporte, vestuário, e outras áreas (BERGER, 2018).

Como há um crescente interesse na produção de nanomateriais, deve-se considerar o potencial destes materiais como contaminantes ambientais. Assim, ainda existem inúmeras questões sem respostas, que precisam ser discutidas e refletidas, como por exemplo, quais são as principais vias de contato/interação dos nanomateriais com os biossistemas? Através de qual meio (aquático, aéreo ou terrestre) os nanomateriais penetram no ambiente? São solúveis em água? Qual é a toxicidade desses materiais frente aos biossistemas? Quais mecanismos de interação estão envolvidos? É possível remover ou remediar nanomateriais do ambiente caso ocorra algum acidente? Qual é o ciclo de vida dos produtos contendo esses materiais nanométricos? (MARTINEZ, ALVES, 2013, p.33).

Discorrem Baruah e Dutta (2009, p.201-202) sobre o risco e formas de entrada de nanopartículas no corpo humano, em que as partículas podem interferir na sinalização celular e levanta questões sobre segurança e efeitos adversos. Outro estudo demonstra possíveis efeitos tóxicos no cérebro (neurotoxicidade) dos peixes Zebrafish (Danio rerio) expostos aos nanotubos de carbono (DALFORNO et al, 2013). Compostos da indústria de nanotecnologia, como os nanomateriais à base de carbono, são fortes candidatos a contaminar ambientes aquáticos, pois sua produção e eliminação têm crescido exponencialmente em poucos anos, sem que se tenha estudos conclusivos sobre a sua efetiva interação com o meio ambiente. Recente estudo demonstrou que o fulereno C6o diminuiu a viabilidade das células e prejudicou a detoxificação de enzimas, evidenciando interações toxicológicas (FERREIRA et al., 2014).

4 O ser humano está construindo um mundo perigoso, parafraseando um livro de DELMAS-MARTY, Mireille. Libertés et sûreté dans un monde dangereux. 2010. 
Apesar destas evidências, os gastos direcionados pela National Nanotechnology Initiative $(N N I)$, dos Estados Unidos, para o desenvolvimento de produtos a partir da escala nanométrica são muito superiores do que os gastos com testes de segurança (BEHAR; FUGERE; PASSOFF, 2013): em 2011, foram gastos 1,847 bilhões de dólares com o desenvolvimento de produtos, contra 88 milhões de dólares para testes de segurança (saúde e segurança ambiental); já em 2012, foram gastos 1,69o bilhões de dólares com o desenvolvimento de produtos, contra 102,7 milhões de dólares para a realização de testes de segurança; para o ano de 2013, foram propostos os seguintes valores: 1,76o bilhões de dólares para o desenvolvimento de produtos e 105,4 milhões de dólares para testes de segurança. Estes números mostram a ampla valorização dos aspectos positivos (as possibilidades) prospectadas para as nanotecnologias, que acabam obnubilando os estudos sobre riscos que a manipulação em nano escala poderão gerar (os aspectos negativos).

Além dos estudos sobre a toxicidade dos nanomateriais, as estratégias de gestão de risco para prevenir a exposição dos trabalhadores e evitar mais amplos problemas de saúde pública devem ser desenvolvidas por instituições de pesquisa, indústrias e agências governamentais.

A Política Nacional de Nanotecnologia precisa incorporar, de forma mais sistemática e estimular com instrumentos mais concretos, a investigação dos impactos econômicos, sociais, legais e éticos das nanotecnologias, reforçar os estudos sobre riscos à saúde e ao meio ambiente e as estratégias de comunicação pública sobre o conjunto de questões relacionadas com estas tecnologias emergentes (INVERNIZZI et al, 2008, p. 79).

Portanto, há evidências científicas de que os riscos poderão ser produzidos a partir de múltiplas fontes. Apesar das promessas substanciais da nanotecnologia, se vislumbram várias áreas de preocupação, que motivam os atuais pedidos por regulação. Uma vez que se apresenta o contexto de risco, necessário que seja fomentado e protegido o Direito à informação, proporcionando ao consumidor que o mesmo possa efetuar sua opção pelo produto, ciente dos riscos.

\footnotetext{
Entre os possíveis riscos estão: a) a segurança do trabalhador na fabricação ou uso de partículas nanométricas; b) a segurança do consumidor na utilização ou aplicação de bens baseados na tecnologia nanotecnológica; c) danos ambientais causados pela produção de resíduos e fabricação de produtos acabados que possam contaminar o ar, a água ou o solo; d) convulsões socioeconômicas, incluindo rupturas econômicas em economias baseadas em agricultura, matérias-primas ou trabalho; e) consequências imprevistas de nanotecnologias descontroladas; f) uso governamental/estatal de nanotecnologias para conter as liberdades civis; g) aplicações militares; h) uso das nanotecnologias nas mãos de terroristas ou outros criminosos (MARCHANT, SYLVESTER, 2006, p. 714-725).
}

Vale dizer, há mais perguntas do que respostas (BUBZY, 2010, p. 530) Os impactos nocivos e riscos potenciais à saúde humana e animal, ao meio ambiente e até em relação ao comportamento humano são ainda pouco conhecidos (ABDI, 2010, p. 40). Para a avaliação desses aspectos, deverão ser aperfeiçoados e desenvolvidos testes que busquem identificar: “(i) suas propriedades físico-químicas; (ii) seu potencial de degradação e de acumulação no meio ambiente; (iii) sua toxicidade ambiental: e (iv) sua toxicidade com relação aos mamíferos" (ABDI, 2010, p. 41).

É preciso que as informações decorrentes do estudo dos riscos tenham ampla divulgação e estejam disponíveis para a sociedade consumidora, ou seja, para que os atores envolvidos diretamente nas decisões sobre a limitação ou não do uso das nanotecnologias e a sociedade civil tenham melhores condições frente aos desafios surgidos com esta nova tecnologia. Os instrumentos fundamentais para uma eficiente organização dos processos de gestão de risco 
nas sociedades contemporâneas são a participação, o desenvolvimento do significado jurídico da precaução e principalmente, a proteção do direito à informação ambiental de qualidade (AYALA, 2001).

A gestão dos riscos naturais, tecnológicos ou sociais solicita a multiplicação de atores e não pode ser colocada somente em termos técnicos ou estritamente securitários. As negociações devem envolver agências multilaterais, governos dos estados, empresas, associações ou grupos de pressão e a sociedade em geral, de modo a esclarecer os fatos que desencadeiam os riscos e determinar as condições para seu enfrentamento. (ZANIRATTO et al, 2008).

Ante a complexidade desta nova tecnologia, refletindo em possíveis impactos danosos às futuras gerações (bem como ainda poderá atingir a atualidade), urge que o Sistema do Direito procure uma alternativa jurídica a fim de proporcionar a proteção do consumidor através do dever/direito à informação, estabelecendo que se apresentem tanto os pontos benéficos desta nova tecnologia quanto os potenciais danos e cenário de risco.

A sociedade tem o direito fundamental de saber a composição dos produtos do mercado, e este é um pré-requisito para o exercício do direito de escolher o que consumir. Torna-se necessária a discussão acerca do princípio da informação, corolário do dever de informação que cabe ao produtor, visando à proteção do consumidor de produtos nanotecnológicos.

\section{DIREITO/DEVER DEINFORMAÇÃO NO CONTEXTODAS NANOTECNOLOGIAS: É POSSÍVEL ENCONTRAR DISPOSITIVOS PROTETIVOS AO NANOCONSUMIDOR NA LEGISLAÇÃO BRASILEIRA?}

A gestão do risco permeia o direito à informação e o dever de informar. Mas e quem faz esta gestão? Para quem ela é feita? Como se poderá fazer esta gestão? "Na verdade, não temos problema algum em gerenciar riscos, mesmo riscos de vida. $\mathrm{O}$ que o indivíduo não aceita é que um risco de dano a ele seja gerenciado por outrem, sem seu devido conhecimento e sua completa compreensão" (HARTMANN, 2011, p. 544). Este é o ponto: por meio das nanotecnologias são elaborados produtos novos, apresentam partículas com características físico-químicas desconhecidas, mas são adicionadas sem nenhum controle, submetendo o consumidor a riscos incalculáveis.

O avanço das nanotecnologias, num conjunto crescente de aplicações, começa a integrar o cotidiano da sociedade brasileira e mundial. Por outro lado, as pesquisas e os produtos que advirão desta intervenção humana nas forças naturais exigirão a divulgação das informações ao mercado produtor e consumidor, pois há, inclusive, previsão constitucional deste direito fundamental, qual seja, o "direito à informação", como um direito subjetivo que nasce com o dever subjetivo do empresário: o "dever de informar".

O direito à informação trata de um direito coletivo da informação ou do direito da coletividade à informação; o direito de informar, como aspecto da liberdade de manifestação do pensamento, revela-se um direito individual, mas já contaminado de sentido coletivo, em virtude das transformação de meios de comunicação, de sorte que a caracterização mais moderna do direito de comunicação, que especialmente se concretiza pelos meios de comunicação social ou de massa. Ao lado do direito individual corrobore-se o direito coletivo (SILVA, 2005, p. 259).

Foi levando em consideração a insegurança - principalmente ocupacional - quanto à utilização da nanotecnologia na indústria que a Fundação CERTI, referência nacional e internacional no suporte para a indústria no quesito das tecnologias inovadoras, desenvolveu 
uma Cartilha de Nanossegurança, que bem define a necessidade de cuidado quando o assunto é nanotecnologia:

\begin{abstract}
Porém, as pequenas (ou nano!) diferenças em tamanho das partículas, formato, área superficial e/ou outras características, podem modificar drasticamente a funcionalidade, a qualidade, a e ciência e, é certo, a toxicidade do nanomaterial e do produto final para quem o utilizar. A Nanossegurança entra aí! A abordagem que trata essa cartilha tem como base o paradigma Safety by Design (Segurança obtida pelo Projeto). Porém, inclui também aspectos de segurança ocupacional (para os trabalhadores das empresas), tratando da segurança das pessoas em toda a cadeia da produção e do uso dos nanoprodutos. (CERTI, 2016).
\end{abstract}

Trata-se de investir no Direito à Informação: quem consome os produtos desenvolvidos com nanotecnologia tem o direito de saber das mudanças e dos seus efeitos positivos e negativos, permitindo uma escolha consciente dos produtos que carregam essas novidades. Diversos países, dentro dos quais França, Bélgica, Suécia, Noruega, Dinamarca, China e Canadá estabeleceram a obrigatoriedade do registro pelas empresas que vendem produtos contendo nanoparticulas, independente de serem por elas produzidos ou importadas. Também países como Austrália, Estados Unidos, Suiça e Coréia elaboraram definições operativas de nanomateriais, mesmo que nem sempre vinculantes (ENGELMANN et al, 2015, p.87).

Um exemplo importante é quanto aos cosméticos contendo nanotecnologia, amplamente consumidos. Neste campo, dos nanocosméticos, é que se encontrou um primeiro passo para a efetivação desses direitos de informação, a nível internacional, observando o Regulamento (CE) no 1223/2009 do Parlamento Europeu e do Conselho (UNIÃO EUROPEIA, 2009), que inovou ao ressaltar a necessidade de garantir uma avaliação da segurança do produto nanocosmético e ampla divulgação dos riscos associados a sua utilização. $\mathrm{O}$ documento dispões da seguinte forma:

\begin{abstract}
(29) Odesenvolvimento da tecnologia podelevara uma maiorutilizaçãodenanomateriais nos produtos cosméticos. A fim de garantir um elevado nível de protecção dos consumidores, a livre circulação de mercadorias e a segurança jurídica dos fabricantes, é necessário elaborar uma definição uniforme dos nanomateriais a nível internacional. A Comunidade deverá procurar chegar a acordo sobre uma definição nos fóruns internacionais relevantes. Caso tal acordo seja obtido, a definição de nanomateriais constante do presente regulamento deverá ser adaptada em conformidade.
\end{abstract}

(30) Actualmente, a informação sobre os riscos associados aos nanomateriais é inadequada. A fim de avaliar melhor a sua segurança, o CCSC deverá prestar orientação, em colaboração com os organismos competentes, sobre metodologias de ensaio que tenham em conta as características específicas dos nanomateriais.

Dito desta maneira, percebe-se que o Brasil apresenta-se atrasado com relação a outros países do mundo em que esse assunto ganhou grande relevância. No ordenamento jurídico pátrio, inexiste atualmente qualquer legislação específica em vigor que oriente a utilização, a produção e a informação dos produtos contendo nanotecnologia.

Uma possível resposta que pode ser traçada no ordenamento jurídico atual envolve o Direito à Informação. Por estar efetivado na Constituição Federal do Brasil de 1988 no artigo $5^{\circ}$, inciso XIV, que dispõe da seguinte forma: "É assegurado a todos o acesso à informação e resguardado o sigilo da fonte, quando necessário ao exercício profissional", temos constitucionalmente garantida a exigência irrenunciável da comunicação quanto a utilização das nanotecnologias nos produtos cosméticos e as suas potencialidades de risco, devendo ser "reconhecido e positivado na esfera do direito constitucional positivo" (SARLET, 2003). 
Portanto, encontra-se disposto no artigo $5^{\circ}$, incisos IV, XVI e XXXIII cumulado com os artigos 220 a 224. "É o interesse geral contraposto ao interesse individual da manifestação de opinião, ideias e pensamento, veiculador pelos meios de comunicação social. Daí por que a liberdade de informação deixará de ser mera função individual para tornar-se função social”. (SILVA, 2005, p. 260).

O Direito/Dever à Informação também tem respaldo no Código de Defesa do Consumidor. Levando em conta a grande quantidade de produtos contendo nanotecnologia lançados diariamente ao mercado, o primeiro afetado com possíveis danos que esta novidade pode causar serão os consumidores, leigos no trato com essa tecnologia emergente. Por tal razão, quem consome tais produtos tem o direito de saber dos efeitos e mudanças físicoquímicas dessas partículas.

Diante de tal realidade, o Código de Defesa do Consumidor (Lei no $\mathbf{8 . 0 7 8}$, de 11 de setembro de 1990), pode projetar mecanismos que garantam a informação ao consumidor quanto as potencialidades das nanotecnologias. Em primeiro lugar, ao elencar os direitos básicos do consumidor no Artigo 6oㅡ, o legislador trouxe a garantia da informação em seus incisos II e III5.

Expicando o inciso III, Grinover et al ( 2011, p. 153) salienta:

É indispensável, por conseguinte, que haja uma ligação permanente, ou um elo de comunicação constante entre fornecedores/consumidores para que esses últimos possam efetivamente ter acesso à informações sobre os produtos e serviços.

A sociedade tem o direito fundamental de saber a composição dos produtos que estão à venda no mercado. É um pré-requisito para o exercício de outro direito, ou seja, o direito de escolher, de optar. Ainda no CDC observa-se outro dispositivo importante. O Código de Defesa do Consumidor (CDC), por meio do seu art. $31^{6}$, estabelece uma série de requisitos que deverão ser observados quando os produtos são colocados em comercialização. Este dispositivo legal carrega no seu seio uma efetiva caracterização de elementos necessários para se conhecer o produto comprado. No entanto, não basta somente isso. A informação deverá vir acompanhada de educação. É insuficiente colocar uma série de informações no rótulo ou na propaganda do produto. Será necessário educar o consumidor para ler e interpretar, conhecer e compreender o seu conteúdo (ENGELMANN, CHERUTTI, 2013). O pleno exercício do direito à informação, que é do consumidor, depende de um aspecto preliminar: a prática do dever de informação, que é do fabricante e do comerciante. Assim, se tem uma reciprocidade e complementariedade entre direito e dever, os quais assumem importância peculiar no caso das nanotecnologias.

No caso do citado art. 31, do CDC, há uma referência expressa à obrigação de se informar os riscos que o produto possa gerar em relação à saúde e segurança dos consumidores. Constatase uma falha na comunicação entre os Sistemas do Direito, da Economia e da Ciência. Esta última deverá buscar subsídios para que o Sistema do Direito possa decidir, observando as diretrizes oriundas do Sistema Econômico. Há uma marcada incerteza em todos os Sistemas Sociais que são chamados a operar com as nanotecnologias.

No caso do Sistema do Direito esta situação vem caracterizada pela inadequação da formulação legislativa consumerista relacionada ao direito à informação. Os produtos contendo

5 Art. $6^{\circ}$ São direitos básicos do consumidor:

[...]

II - a educação e divulgação sobre o consumo adequado dos produtos e serviços, asseguradas a liberdade de escolha e a igualdade nas contratações;

III - a informação adequada e clara sobre os diferentes produtos e serviços, com especificação correta de quantidade, características, composição, qualidade, tributos incidentes e preço, bem como sobre os riscos que apresentem;

6 "A oferta e apresentação de produtos ou serviços devem assegurar informações corretas, claras, precisas, ostensivas e em língua portuguesa sobre suas características, qualidades, quantidades, composição, preço, garantia, prazos de validade e origem, entre outros dados, bem como sobre os riscos que apresentam à saúde e segurança dos consumidores". 
nanopartículas estão chegando ao mercado, mas os consumidores não estão recebendo as informações adequadas, a fim de poderem exercer democraticamente o exercício de comprar ou não (ENGELMANN, HOHENDORFF, 2014).

A concretização do direito à informação auxilia na construção de um ambiente de participação democrática dos cidadãos. A concretização dessa figura constitucional (possuidora de alta carga democrática) parece ser o modelo capaz de garantir um poder cidadão, objeto das alienações e descumprimento, por parte do Poder Público (BONAVIDES, 2001, p. 25).

O "direito de saber" como a estrutura central do "direito à informação", que é destinado à sociedade, e do "dever de informação", dirigido ao pesquisador e empresário, deverá ser perspectivado desde o trabalho com a matéria-prima, ou seja, a produção material em estado bruto, onde se terá a exposição direta do trabalhador, além da emissões industriais. Este conjunto já atinge a população humana e o meio ambiente. Os produtos manufaturados vão ao mercado consumidor, onde eles são adquiridos, com a exposição dos consumidores, isto é, toda a sociedade. A terceira etapa é aquela onde os produtos serão descartados, incluindo as embalagens, que irão aos grandes espaços de depósito do lixo e incineração, onde teremos nova exposição dos trabalhadores e, concomitantemente, a população humana e o meio ambiente. Neste pequeno e singelo exemplo de ciclo de vida de um produto com nanopartícula mostra as diversas formas de exposição, onde se exigirá o conhecimento do que se está manipulando e quais os riscos. (ENGELMANN, 2015, p. 359-36o)

Assim, "a informação, ao passar conhecimentos, vai ensejar da parte do informado a criação de novos saberes, através do estudo, da comparação ou da reflexão." (MACHADO,20o6. p. 27.)

O cerne do "direito de saber" é justamente este conhecimento mínimo sobre os progressos científicos que são gerados nos laboratórios e, muitas vezes, fomentados pelo próprio Estado, por meio de seus órgãos de fomento (CAPES, CNPq, FINEP, FAPERGS, entre outros). Em cada momento do ciclo de vida dos nano produtos deverá ser gerado uma espécie de conhecimento que seja adequado e compreensível pelos sujeitos envolvidos (ENGELMANN, 2015, p. 360).

Resta a questão: Qual a alternativa para dar conta desta situação? O direito à informação não é exercido e o dever de informação tampouco é estimulado. Um "cuidado" anexo à abordagem precaucional é a informação e o fomento à participação pública sobre as decisões que envolvam as nanotecnologias. Não há uma resposta pronta para esta nova realidade que nos deparamos, mas é fundamental que se dê o primeiro passo e não se esquecer:

[...] para fazer evoluir a cultura científica importa que o público seja bem informado e participe, com conhecimento de causa, em debates. Promover a cultura científica faz parte de uma boa higiene democrática. É indispensável para permitir ao público compreender a orientar o progresso. O "direito de saber", ou o "direito de ser informado", integra o planejamento da sociedade inscrito na essência do Estado Democrático de Direito. (ENGELMANN, 2015, p. 363).

O exercício do direito à informação pelos seus titulares, provocará a necessária prática do dever de informação.

Portanto, verifica-se a necessidade da utilização do princípio da informação para proporcionar ao consumidor a autonomia de escolha dos produtos, cientificando-os dos riscos que possam ser produzidos pelo consumo destes. É importante a efetiva aplicação do princípio da informação de modo que a sociedade possa compreender a dimensão que assume a defesa do consumidor frente aos possíveis riscos dos produtos nanotecnológicos.

O contexto assim observado se mostra desafiador para o Direito, pois terá que lidar com os danos futuros, a partir de decisões que deverão ser tomadas no presente. Vale dizer, 
o Direito se vê confrontado com uma situação de incerteza e complexidade, que precisará ser respondida criativamente e por meio de ferramentas diferentes daquelas tradicionalmente fornecidas pelo positivismo jurídico, especialmente aquele de viés legalista.

A sociedade atual está vivendo o período da revolução nanotecnológica, onde os mais diversos setores produtivos utilizam em seus processos insumos, materiais ou equipamentos que contém nanopartículas engenheiradas. As pesquisas em nano escala já deixaram os laboratórios e ganharam as linhas de produção das indústrias, incrementando o número de produtos com nanotecnologia que chegam ao mercado. Assim, uma coisa é certa: a responsabilidade em relação às gerações futuras e o cuidado com o patrimônio natural começam aqui e agora. Eles não têm outro advogado de defesa que não o cidadão, consumidor carente de mais informações para que possa participar ativamente também na gestão dos riscos e fazendo suas escolhas pessoais de consumo.

Por isso, ao invés daquelas características do positivismo jurídico, busca-se ampliar a efetividade, a adequação das respostas às perguntas formuladas pelas novas e nanotecnologias (ENGELMANN, 2013, p. 260). Tais mudanças profundas no Sistema do Direito se fazem urgentes e necessárias, a fim de possibilitar o seu diálogo com os demais Sistemas, especialmente o Sistema da Ciência, com o foco no equacionamento dos eventuais riscos que poderão vir junto com o aprofundamento da Revolução Nanotecnológica, a começar pelo respeito e promoção do direito/dever da informação, que possibilitará ao consumidor o mínimo de conhecimento sobre tais novas tecnologias, para que esteja ciente de suas escolhas, principalmente quanto aos riscos.

Desta forma, cabe ao Direito, como ciência, possibilitar a criação de instrumentos jurídicos com objetivo de efetivar medidas de gerenciamento preventivo do risco, baseado nos princípios da prevenção, da precaução, da responsabilização, da informação e da sustentabilidade, objetivando sempre o cuidado com o ser humano e o meio ambiente.

\section{CONSIDERAÇÕES FINAIS}

A recente quebra de paradigma do poder das novas tecnologias vem despertando uma preocupação iminente no que tange à proteção, saúde e bem-estar humano. O aprofundamento do debate sobre os riscos mostra-se indispensável no atual contexto nanotecnológico. Pelo que se depreende do estudo de vasta bibliografia e notícias científicas recentes, a produção de nanoprodutos encontra-se em amplo crescimento, o que consequentemente gera o aumento do risco na utilização desavisada destes produtos.

Não há certeza sobre os (possíveis) danos ou efeitos que as nanos poderão acarretar na saúde humana, em especial quanto à toxicidade e a ausência de biocompatibilidade dos materiais utilizados. Isso é ainda mais gravoso pelo contato direto que os consumidores têm com esses produtos amplamente lançados ao mercado.

Uma vez que a nanotecnologia está amplamente inserida no cotidiano, através de inúmeros produtos apresentados ao longo deste artigo, necessário que seja adotada uma conduta minimamente precaucional, projetando assim o máximo de informação disponível aos consumidores, para que estes possam optar pela utilização consciente destes produtos inovadores. O desafio da nanotecnologia na atualidade, para o Direito, é como a sociedade poderá colher os benefícios da produção em nano escala e, concomitantemente não sofrer os danos associados com a saúde humana e riscos ambientais que podem advir juntamente com esta tecnologia. Não há hoje, conhecimento disponível para definir todos os possíveis riscos associados aos nanomateriais, e assim, se torna necessária e imprescindível a gestão dos riscos 
para que as decisões possam objetivar a redução deles. Embora não se possa "conhecer" todos os resultados possíveis associados aos nanomateriais e nanotecnologias, é importante que as decisões sobre o desenvolvimento da nanotecnologia sejam orientadas para a redução do risco. (DANA, 2012. Prefácio.).

O pleno exercício do direito à informação, que é do consumidor, depende de um aspecto preliminar: a prática do dever de informação, que é do fabricante e do comerciante. Assim, se tem uma reciprocidade e complementariedade entre direito e dever, os quais assumem importância peculiar no caso das nanotecnologias.

Neste sentido, o direto do consumidor também sofre impactos, especialmente no tocante ao direito de informação, que permitirá ao consumidor poder realmente fazer uma opção de consumo. Ainda, concomitantemente a este direito surge para o empreendedor o dever de informação.

O direito à informação não se configura apenas como um direito infraconstitucional, mas como um dos direitos do consumidor, radica no interesse público, considerando que "[...] sua tessitura está coenvolvida de inevitáveis inserções no âmbito do Direito Público Constitucional, até porque as relações de consumo são necessariamente transindividuais, pois irradiam efeitos além dos sujeitos concretos da aquisição ou utilização de determinado produto para alcançar todos os que sejam por elas atingidos, em ato ou potência" (LÔBO, 2011, p. 596). Os direitos do consumidor são uma categoria jurídica onde se expressa a genuína constitucionalização do Direito Privado. Um conjunto de relações que emergem na seara privada, que passam a receber o manto público da Constituição, quando a proteção e a defesa do consumidor são guindados a direitos fundamentais e direitos integrantes da ordem econômica do Estado.

O cumprimento voluntário do direito/dever à informação, por parte de todos os envolvidos, corresponde à uma das condutas eticamente responsáveis e proporciona de igual modo, um consumo consciente.

É imprescindível a observação e respeito à limites mínimos no desenvolvimento desta nova tecnologia, prezando precipuamente ao bem-estar e segurança da vida humana. No horizonte atual de riscos envolvendo os produtos nanotecnológicos, aparece o Direito com um papel regulatório de construção de elementos adequados para tutelar esta nova demanda, viabilizando o Direito à Informação visto sob a ótica da dignidade da pessoa humana e por sua vertente positivada (presente na Constituição e no Código de Defesa do Consumidor, em especial no seu artigo 31). O fato é que o Consumidor tem o Direito (Dever) de conhecer os benefícios e riscos dos produtos a serem consumidos. Para isso, faz-se necessário construir alternativas para esclarecer o público consumidor leigo.

\section{REFERÊNCIAS}

ABBONDANZA, Sébastien. Les Enjeux de larobotique. IN: Destination Science Les Thématiques, Naintré, França, n. 1, novembre 2015.

\section{ABDI. AGÊNCIA BRASILEIRA DE DESENVOLVIMENTO INDUSTRIAL. Estudo prospectivo nanotecnologia. Brasília: ABDI, 2010.}

AYALA, Patryck de Araújo. Transdisciplinaridade e os novos desafios para a proteção jurídica do meio ambiente nas sociedades de risco: entre direito, ciência e participação, Revista de Direito Ambiental, São Paulo, a. 16, n. 61, p. 17-36, jan./mar. 2011. 
BARBAT, A. S. Estudios de Derecho de Seguros y Reaseguros. La Ley Uruguay, Montevideo, 2016, p. 213.

BARUAH, S; DUTTA, J. Nanotechnology applications in pollution sensing and degradation in agriculture: a review. Environmental Chemistry Letters, Secaucus, v. 7, n. 3, p. 201-202, Sept. 2009. Disponível em: <https://link.springer.com/article/10.1007/s10311-009-0228-8>. Acesso em: o5 jun. 2018.

BEHAR, Andrew; FUGERE, Danielle; PASSOFF, Michael. Slipping Through the Cracks: An Issue Brief on Nanomaterials in Food. As You Sow, 2013. Disponível em: <www.asyousow. org/health_safety/nanoissuebrief.shtml> Acesso em: 04 nov. 2013.

BERGER, Michael. A nanotechnology perspective for manufacturing. Disponível em: <http:// www.nanowerk.com/spotlight/spotid=44211.php>. Acesso em: o8 jul. 2018.

BONAVIDES, Paulo. Teoria Constitucional da Democracia Participativa. São Paulo: Malheiros Editores, 2001.

BUZBY, Jean C. Nanotechnology for food applications: more questions than answers. The Journal of Consumer Affairs, v. 44, n. 3, 2010.

CHENG, Huai. N. et al. Nanotechnology overview: opportunities and challenges. In: CHENG, Huai. N. et al. (Ed.). Nanotechnology: delivering on the promise. Washington: American Chemical Society, 2016. v. 1. (ACS Symposium Series, 1220).

CHRISTENSEN, Frans Møller et al. Better control of nanomaterials: summary of the 4-year Danish iniciative on nanomaterials. Copenhagen: The Danish Environmental Protection Agency, 2015. (Environment protect, n. 1797). Disponível em: <http://www2.mst.dk/Udgiv/publications/ 2015/12/978-87-93352-89-6.pdf>. Acesso em: o8 jun. 2018.

DAL FORNO, Gonzalo Ogliari et al. Intraperitoneal exposure to nano/microparticles of fullerene (c60) increases acetylcholinesterase activity and lipid peroxidation in Adult Zebrafish (Danio rerio) Brain. BioMed Research International, New York, v. 2013, 2013. Disponível em: <https://www. hindawi.com/journals/ bmri/2013/623789/abs/>. Acesso em: 04 jul. 2018.

DANA, David A. The Nanotechnology Challenge: creating legal institutions for uncertain risks. New York: Cambridge University Press, 2012.

DELMAS-MARTY, Mireille. Libertés et sûreté dans un monde dangereux. Éditions du Seuil, Paris, 2010.

DURÁN, N.; MATTOSO, L. H. C.; MORAIS, P. C. de. Nanotecnologia: introdução, preparação e caracterização de nanomateriais e exemplos de aplicação. Artliber, São Paulo, 2006. 
ENGELMANN, W. O pluralismo das fontes do Direito como uma alternativa para a estruturação jurídica dos avanços gerados a partir da escala manométrica. STRECK, L. L.; ROCHA, L. S.; ENGELMANN, W. (Org.). Constituição, Sistemas Sociais e Hermenêutica - Anuário do Programa de Pós-Graduação em Direito da Unisinos. Livraria do Advogado Editora, Porto Alegre, 13, p. 247-259, 2017.

ENGELMANN, Wilson et al (Org.). Nanocosméticos e o Direito à Informação.: Construindo os Elementos e as Condições para Aproximar o Desenvolvimento Tecnocientífico na Escala Nano da Necessidade de Informar o Público Consumidor. 1.ed. Erechim - Rs: Deviant, 2015.

ENGELMANN, Wilson. Direito Natural, Ética e Hermenêutica. Porto Alegre: Livraria do Advogado, 2007.

ENGELMANN, Wilson. From Pontes de Miranda to Mireille Delmas-Marty: journey to review the Theory of Sources of Law to accommodate the new rights generated by Nano Technological Revolution. IN: XXVI World Congress of Philosophy of Law and Social Philosophy: Human Rights, Democracy, Rule of Law and Contemporary Social Challenges in Complex Societies. Belo Horizonte: Fórum, 2013.

ENGELMANN, Wilson. Nanotechnology, Law and Innovation. Germany: LAP LAMBERT Academic Publishing, 2011.

ENGELMANN, Wilson. O "direito de ser informado" sobre as possibilidades e os riscos relacionados às nanotecnologias: o papel do engajamento público no delineamento de um (novo) direito/dever fundamental. In: MENDEs, Gilmar Ferreira, SARLET, Ingo Wolfang, COELHO, Alexandre Zavaglia P. (Org.). Direito, inovação e Tecnologia. São Paulo: Saraiva, 2015 .

ENGELMANN, Wilson. Os avanços nanotecnológicos e a (necessária) revisão da Teoria do Fato Jurídico de Pontes de Miranda: compatibilizando "riscos" com o "direito à informação" por meio do alargamento da noção de "suporte fático". IN: Callegari, A.L.; Streck, L.L. Rocha, L.S. (Orgs.). Constituição, Sistemas Sociais e Hermenêutica: Anuário do Programa de Pós-Graduação em Direito - Mestrado e Doutorado - da Unisinos. Porto Alegre: Livraria do Advogado, n. 8, p. 339-363, 2011.

ENGELMANN, Wilson; CHERUTTI, Guilherme. Da Educação ao Direito à Informação: desafios e possibilidades para estes direitos fundamentais na Era das Nanotecnologias. IN: ENGELMANN, Wilson; SCHIOCCHET, Taysa (Coords.). Sistemas Jurídicos Contemporâneos e Constitucionalização do Direito: releituras do Princípio da Dignidade Humana. Curitiba: Juruá, 2013.

FERREIRA, Jonsecler L. Ribas et al. Co-exposure of the organic nanomaterial fullerene C6owithbenzo[a]pyrene in Danio rerio (zebrafish) hepatocytes: evidence of toxicological interactions. Aquatic Toxicology, Amsterdam, v. 147, Feb. 2014. Disponível em: <http://www. science direct.com/science/article/pii/So166445X13003482>. Acesso em: 04 jul. 2018.

FUNDAÇÃO CERTI. Nanossegurança na Prática. 2016. Disponível em: <http://insights. certi.org.br/nanosseguranca-na-pratica/>. Acesso em: 19 fev. 2018. 
GERMANY. Federal Ministry of Education and Research. Action plan nanotechnology 2o2o: an inter-departmental strategy of the Federal Government. Rostock, Oct. 2016. Disponível em: <https://www.bmbf. de/pub/Action_Plan_Nanotechnology.pdf>. Acesso em: 15 fev. 2018.

GRINOVER, Ada Pellegrini et al. Código brasileiro de defesa do consumidor: comentado pelos autores do anteprojeto. 10. ed., rev., atual. e reform. Rio de Janeiro: Forense Universitária, 2011.

HARTMANN, Ivar Alberto Martins. O Princípio da Precaução e sua Aplicação no Direito do Consumidor. Dever de Informação. IN: MARQUES, Cláudia Lima; MIRAGEM, Bruno (Orgs.). Doutrinas Essenciais. Direitos do Consumidor. São Paulo: RT, v. 3, p. 579-614, 2011.

HOHENDORFF, Raquel Von; ENGELMANN, Wilson. Nanotecnologias aplicadas aos agroquímicos no Brasil: a gestão dos riscos a partir do Diálogo entre Fontes do Direito. Curitiba: Juruá, 2014.

INTERNATIONAL ORGANIZATION FOR STANDARDIZATION (ISO). ISO/TC 229: nanotechnologies. Geneva, 2005. Disponível em: <http://www.iso.org/iso/iso_technical_ committee?commid=381983>. Acesso em: 07 abr. 2018.

INTRODUCTION. Nanotechnology Products Database (NPD). [S.l.], 2017. Disponível em: $<$ http:// product.statnano.com/>. Acesso em: 24 jun. 2018.

INVERNIZZI, Noela; KÖRBES, Clecí; FUCK, Marcos Paulo. Política de Nanotecnología em Brasil: a 10 años de las primeras redes. In: FOLADORI, Guillermo; INVERNIZZI, Noela. Nanotecnologias en la Alimentación y Agricultura. Montevideo: Universidad de La Republica, 2008.

KIMBRELL, George A. Governance of nanotechnology and nanomaterials: principles, regulation, and re-negotiating the social contract. Journal of Law, Medicine and Ethics, a. 37, n. 706, Winter. 2009. Disponível em: <http://www.icta.org/files/2012/05/100993_Nano_ and_You_lo.pdf>. Acesso em: 16 mar. 2014.

LÔBO, Paulo Luiz Netto. A Informação como Direito Fundamental do Consumidor. IN: MARQUES, Cláudia Lima; MIRAGEM, Bruno (Orgs.). Doutrinas Essenciais. Direitos do Consumidor. São Paulo: RT, v. 3, p. 527-82, 2011.

MARCHANT, G. E. and SYLVESTER, D. J.Transnational Models for Regulation of Nanotechnology. Journal of Law, Medicine and Ethics, p. 714-725, Winter 2006, esta passagem se encontra na p. 716. Disponível em: <https://ssrn.com/abstract=907161>. Acesso em: 30 mar. 2018.

MARTINEZ, Diego Stefani Teodoro; ALVES, Oswaldo Luiz. Interação de nanomateriais com biossistemas e a nanotoxicologia: na direção de uma regulamentação. Revista da Sociedade Brasileira para o progresso da ciência, a. 65, n. 3, jul/ago/set, 2013. 
PNUMA - Programa de las Naciones Unidas para el Medio Ambiente. Fronteras 2o17. Nuevos temas de interés ambiental. Programa de las Naciones Unidas para el Medio Ambiente, Nairobi, 2017,

SARLET, Ingo Wolfgang. A Eficácia dos Direitos Fundamentias. 3.ed. rev. atual e ampl. Porto Alegre: Livraria do Advogado, 2003.

SILVA, José Afonso. Direito Constitucional Positivo. 25. ed. São Paulo: Editora Malheiros, 2005 .

SUPPAN, Steve. No Small Task: Generating Robust Nano Data. Posted July 16, 2015. Disponível em: <http://www.iatp.org/blog/201507/no-small-task-generating-robust-nanodata>. Acesso em: 09 jul. 2018.

UNIÃO EUROPEIA. Comissão Europeia. HORIZON 2020: em breves palavras: o programaquadro de investigação e inovação da EU. Bruxelas, 2014. p. 9-10. Disponível em: <https:// ec.europa.eu/programmes/ horizon2020/sites/horizon2020/files/H2020_PT_KIo213413PTN. pdf>. Acesso em: 18 fev. 2018.

UNIÃO EUROPEIA. Regulamento (ce) N.o 1223/2009 do Parlamento Europeu e do Conselho. União Europeia, 30 nov. 2009. Disponível em: <http://eur-lex.europa.eu/legalcontent/PT/TXT/HTML/?uri=CELEX:32009R1223\&from=PT>. Acesso em: 23 fev. 2017.

VANCE, Marina E. et al. Nanotechnology in the real world: redeveloping the nanomaterial consumer products inventory. Beilstein Journal of Nanotechnol, Frankfurt am Main, n. 6, Aug. 2015. Disponível em: <http://www.beilstein-journals.org/bjnano/content/pdf/2190-42866-181.pdf>. Acesso em: 19 fev. 2018.

ZANIRATO, Silvia Helena; RAMIRES, Jane Z. S.; AMICCI, Anie Gracie Noda; RIBEIRO, Zulimar Márita; RIBEIRO, Wagner Costa. Sentidos do risco: interpretações teóricas revista bibliográfica de geografía y ciencias sociales. Barcelona: Universidad de Barcelona, v. 3, n. 785, Maio 2008. 